University of Nebraska - Lincoln

DigitalCommons@University of Nebraska - Lincoln

Drought Mitigation Center Faculty Publications Drought -- National Drought Mitigation Center

$11-3-2017$

\title{
FLASH DROUGHTS: A Review and Assessment of the Challenges Imposed by Rapid-Onset Droughts in the United States
}

Jason A. Otkin

Mark Svoboda

Eric D. Hunt

Trent W. Ford

Martha C. Anderson

See next page for additional authors

Follow this and additional works at: https://digitalcommons.unl.edu/droughtfacpub

Digitart of the Climate Commons, Environmental Indicators and Impact Assessment Commons, Epmmpnental Monitoring Commons, Hydrology Commons, Other Earth Sciences Commons, and the Wetererkesource Management Commons

Logo

This Article is brought to you for free and open access by the Drought -- National Drought Mitigation Center at DigitalCommons@University of Nebraska - Lincoln. It has been accepted for inclusion in Drought Mitigation Center Faculty Publications by an authorized administrator of DigitalCommons@University of Nebraska - Lincoln. 
Authors

Jason A. Otkin, Mark Svoboda, Eric D. Hunt, Trent W. Ford, Martha C. Anderson, Christopher Hain, and Jeffrey B. Basara 


\title{
FLASH DROUGHTS
}

\section{A Review and Assessment of the Challenges Imposed by Rapid-Onset Droughts in the United States}

\author{
Jason A. Otkin, Mark Svoboda, Eric D. Hunt, Trent W. Ford, Martha C. Anderson, \\ Christopher Hain, and Jeffrey B. Basara
}

It is recommended that the climate features referred to ambiguously as "flash droughts" in the scientific literature be identified based on how rapidly they intensify.

D rought is a naturally recurring feature of the climate system that affects virtually all regions of the world. Extreme drought events such as those that have occurred across various parts of the United States during the past decade have caused major societal disruptions, extensive damage to natural ecosystems, drawdown of surface and groundwater supplies, and sharp reductions in agricultural production. Because droughts occur across multiple time scales (weeks to decades) and exert diverse impacts on different socioeconomic sectors, landscapes, and components of the hydrological cycle, it is difficult to create a uniform definition for drought that applies to all situations. Drought has traditionally been categorized as one of four types: meteorological, agricultural, hydrological, and socioeconomic (Wilhite and Glantz 1985). Meteorological drought refers to a deficit in precipitation over some period of time while taking into account differences in local climatology. If deficits in net water supply at the surface become large, hydrological drought can develop as reflected by groundwater, river, or reservoir levels dropping below normal. When plant water requirements are not met during the growing season, especially during certain periods critical for yield development, agricultural drought can result. Socioeconomic drought considers the impact of drought conditions on the supply and demand of economic goods and services. More recently,
AFFILIATIONS: OTKIN-Cooperative Institute for Meteorological Satellite Studies, University of Wisconsin-Madison, Madison, Wisconsin; SvOBODA—National Drought Mitigation Center, University of Nebraska-Lincoln, Lincoln, Nebraska; HuNT-Atmospheric and Environmental Research, Inc., Lexington, Massachusetts; FORD-Department of Geography and Environmental Resources, Southern Illinois University at Carbondale, Carbondale, Illinois; ANDERSON-Agricultural Research Services, Hydrology and Remote Sensing Laboratory, U.S. Department of Agriculture, Beltsville, Maryland; HAIN-Earth Science Branch, Marshall Space Flight Center, National Aeronautics and Space Administration, Huntsville, Alabama; BASARA-School of
Meteorology, and Oklahoma Climatological Survey, University of Oklahoma, Norman, Oklahoma CORRESPONDING AUTHOR: Jason A. Otkin, jason.otkin@ssec.wisc.edu

The abstract for this article can be found in this issue, following the table of contents. DOI:10.II75/BAMS-D-17-0149.I

In final form 3 November 2017 (02018 American Meteorological Society For information regarding reuse of this content and general copyright information, consult the AMS Copyright Policy. 
a fifth drought type referred to as "ecological drought" has been proposed (Crausbay et al. 2017). This type of drought refers to an episodic deficit in water availability that drives ecosystems beyond thresholds of vulnerability, affects ecosystem services, and triggers feedback between natural and human systems. It should be noted that more than one drought type can occur at the same time at a given location and that droughts can transition from one type to another as conditions and impacts evolve with time.

In addition to these drought types, a potentially new drought type known as "flash drought" has entered the scientific and popular lexicons in recent years. Though a deficit in precipitation is a basic requirement for drought to develop, the speed with which it develops and its ultimate severity are also influenced by other environmental anomalies. For example, if below-normal precipitation is accompanied by above-normal evaporative demand due to high temperatures, low humidity, strong winds, and sunny skies, agricultural and ecological drought conditions signified by increasing soil moisture deficits and declining vegetation health can rapidly emerge. This scenario has occurred in dramatic fashion several times across the United States in recent years. In 2012, large precipitation deficits combined with record-high temperatures and abundant sunshine led to very rapid drought development across the central United States. According to the U.S. Drought Monitor (USDM; Svoboda et al. 2002), widespread areas experienced a three-, four-, or even a five-category increase in drought severity over a 2-month period, which is a remarkable rate of intensification (Fig. 1a). This means that locations that generally had near-normal conditions at the end of May had fallen into extreme drought conditions only two months later. This flash drought had a substantial impact on prime agricultural lands, with losses estimated to be in excess of $\$ 30$ billion across the entire nation (National Centers for Environmental Information 2017). Likewise, in 2016, extreme drought conditions rapidly developed during the fall across a large portion of the southeastern United States, with an extensive area experiencing up to a four-category increase in drought severity over a 3-month period (Fig. 1b). Similar to the 2012 event, this drought had a detrimental impact on agriculture and also led to an elevated fire risk, most notably represented by the devastating wildfires that occurred near Gatlinburg, Tennessee, in late November. The most recent example of rapid drought intensification in the United States occurred across the northern high plains in 2017, where warm and exceptionally dry weather during the spring and early summer led to up to a four-category increase in drought severity over a 2-month period (Fig. 1c) and sharply lower wheat yields across the region. These events demonstrate the suddenness with which extreme drought conditions can develop and the high impact that they have on the economy and local ecosystems. In this paper, we provide an overview of recent research on flash droughts and then present a proposed definition for "flash drought" and a checklist that can be used to track its development. We also discuss the importance of drought monitoring tools and forecasting methods that can quickly capture flash drought onset and predict its evolution over subseasonal time scales.

\section{FLASH DROUGHT LITERATURE REVIEW.}

Drought is often thought of as a slowly evolving climate phenomenon that takes many months or even years to reach its full intensity. However, recent events across the United States and elsewhere around the world have shown that droughts can develop very rapidly if extreme weather anomalies persist over the same region for several weeks to months. Though precipitation deficits over some time period are required for drought to develop, their presence alone is unlikely to lead to a flash drought because a lack of precipitation is only one of several factors that can lead to rapid drought intensification. For example, when precipitation deficits occur alongside other extreme weather anomalies that enhance evaporative demand, such as high temperatures, low humidity, strong winds, and sunny skies, they can work together to quickly deplete soil moisture reserves owing to increased evapotranspiration (ET; Otkin et al. 2013; Anderson et al. 2013). Persistence of such conditions for days to weeks can force a transition from energy-limited ET to waterlimited ET, leading to rapid increases in vegetation stress and the emergence of flash drought (Hunt et al. 2009, 2014; Mozny et al. 2012; Ford et al. 2015; Ford and Labosier 2017). This scenario is most likely to occur during the growing season when evaporative demand is climatologically highest, which exacerbates the impact of flash droughts on agriculture (Otkin et al. 2013, 2016; Hunt et al. 2014; Anderson et al. 2016) and natural ecosystems (Crausbay et al. 2017). Perhaps the earliest mention of this type of phenomenon was made by Lydolph (1964) in reference to the Sukhovey, which is a wind accompanied by high temperatures and low relative humidity that originates in central Asia and primarily occurs during the growing season. Though the term refers to the wind rather than to drought, these events lead to rapid wilting of vegetation and have historically had a major impact on agriculture from eastern Europe to central Asia.

In their introduction to the USDM, Svoboda et al. (2002) coined the term "flash drought" to draw 
attention to the unusually rapid intensification of some droughts and to better distinguish these events from traditional droughts that develop more slowly. Otkin et al. (2013) examined the salient characteristics of rapid-onset flash drought events across the United States using the satellitederived evaporative stress index (ESI; Anderson et al. 2007), which depicts standardized anomalies in a normalized ET fraction given by the ratio of actual ET to potential ET (PET). A detailed analysis of four flash droughts revealed that rapid increases in moisture stress as depicted by rapid decreases in the ESI over several weeks were usually associated with higher air temperatures, fewer clouds, larger vapor pressure deficits, and stronger winds. Given adequate plant-available soil moisture (i.e., energy-limited conditions), rapid increases in both evaporative demand and ET will deplete soil moisture. However, if plant-available soil moisture approaches the wilting point (i.e., waterlimited conditions), such increases in evaporative demand will lead to dramatic decreases in ET and increasing vegetation moisture stress. For example, Hunt et al. (2014) showed that ET from adjacent rain-fed and irrigated corn fields diverged significantly after plantavailable soil moisture in the rain-fed crop dropped below 30\%. Otkin et al. (2013) also showed that change anomalies depicting how rapidly the ESI is changing with time can provide early warning of flash drought development. Otkin et al. (2014, 2015a) subsequently developed the rapid change index (RCI) to encapsulate the accumulated magnitude of moisture stress changes occurring over multiple weeks. These studies showed that droughts are more likely to develop when the RCI is negative and that this likelihood increases dramatically as the RCI becomes more negative.

Several studies have also examined how soil moisture conditions evolve before and during flash drought events. Hunt et al. (2009) developed a soil moisture index (SMI), which is computed using soil moisture observations and estimated wilting and field capacity soil metrics, to examine changes in moisture stress during a flash drought over Nebraska. A subsequent study by Mozny et al. (2012) in the Czech Republic showed that the SMI provides valuable information about the effectiveness of recent rains that can be used to alert agricultural stakeholders about potential drought development. More recent studies by Hunt et al. (2014) and Ford et al. (2015) using soil moisture observations in Nebraska and Oklahoma, respectively, have shown that soil moisture rapidly decreases during the onset phase of a flash drought as a result of increased ET and that soil moisture anomalies tend to initially appear in the topsoil layer before moving deeper into the soil profile. A soil moisture deficit coupled with persistently elevated evaporative demand will eventually result in vegetation stress and the potential development of a flash drought. Ford and Labosier (2017) have also recently shown that periods of rapid soil moisture depletion are typically associated with lower precipitation and humidity and increased solar radiation and temperature, which is consistent with the Otkin et al. (2013) study focusing on ET. By using logistic regression, Ford and Labosier (2017) 
determined that variables accounting for evaporative demand (PET and water vapor pressure deficit) or the balance between the supply and demand of surface moisture (precipitation minus PET) are better predictors of flash drought development than temperature and precipitation are by themselves.

A common theme of these studies is the requirement for the root-zone soil moisture content to rapidly fall below a threshold associated with vegetation moisture stress for it to be considered a flash drought event. This transition from energy-limited to waterlimited conditions is often necessary for soil moisture-atmosphere feedbacks to occur (Seneviratne et al. 2010). It also exemplifies the complex relationship between evaporative demand, soil moisture, and ET. Elevated evaporative demand coupled with initially adequate-to-surplus soil moisture content will result in increased ET and a subsequent depletion of soil moisture reserves. The transition from an energy-limited to water-limited regime occurs when a continuation of enhanced evaporative demand and concurrent decline in root-zone soil moisture leads to vegetation moisture stress and a decrease in ET. Therefore, rapidly declining soil moisture content could potentially serve as a precursor for flash drought, particularly if plantavailable soil moisture is approaching critical levels, such as the wilting point. The switch from adequate to deficit soil moisture conditions will also be evident in datasets such as the ESI as the vegetation responds to soil moisture restrictions by decreasing its ET.

In contrast to the above studies that have identified flash droughts based on an unusually rapid rate of intensification, several other studies have instead focused on their duration. For example, Mo and Lettenmaier (2015, 2016) used pentads (5-day periods) to identify flash droughts based on anomalies in modeled soil moisture, precipitation, ET, and temperature. They suggested that there are two types of flash droughts: "heat wave" flash droughts that are driven by high temperatures and "precipitation" flash droughts that are driven by below-normal precipitation. Heat wave flash droughts require temperature anomalies greater than one standard deviation above normal for a given pentad along with positive ET anomalies and soil moisture content below the 40th percentile. Precipitation anomalies for that pentad are allowed to be positive or negative. In this situation, the unusually high temperatures cause evaporative demand to increase: in energy-limited conditions where there is adequate plant-available soil moisture this leads to decreasing soil moisture; in water-limited conditions where soil moisture is already insufficient to meet the vegetation's needs, this elevated demand is often reflective of decreased ET. Conditions for heat wave flash droughts are mostly likely to be met across the Midwest and Pacific Northwest, where there is dense vegetation. A similar pattern was found by Wang et al. (2016) in which heat wave flash droughts occurred on average twice per year across densely vegetated areas of southeastern China. For precipitation flash droughts, temperature anomalies must again be at least one standard deviation above normal with soil moisture below the 40th percentile; however, for these events, precipitation is also required to be less than the 40th percentile and ET anomalies must be negative in order to distinguish them from heat wave flash droughts. In this case, the precipitation deficits lead to below-normal ET and above-normal temperatures. These conditions occur most often across the southern United States. Overall, their results show that both types in aggregate occur up to several times each year at a given location, with most events lasting no more than two pentads (10 days), thereby making them short, frequent events.

\section{PROPOSED “FLASH DROUGHT” DEFINI-}

TION. As discussed in the previous section, there is currently a lack of consensus in the scientific community concerning the definition of "flash drought"; namely, whether it should be based on how rapidly a drought develops as originally proposed in Svoboda et al. (2002) or instead be based on its duration. Here, we argue that any definition of "flash drought" should inherently account for both its rapid intensification (i.e., the flash) and the actual condition of moisture limitation (i.e., the drought). We propose that flash droughts should be viewed as a subset of all droughts that are distinguished from more conventional slowly developing droughts by their unusually rapid rate of intensification. This definition can be seamlessly applied to all types of drought; however, this essay focuses on agricultural and ecological flash droughts given their large impact on crop yields, livestock forage production, and natural ecosystems. By focusing the definition of "flash drought" on the development phase, we allow for situations where a flash drought that initially impacts agriculture ultimately develops into long-term hydrological drought, such as occurred across parts of the central United States in 2012. That year, widespread areas experienced a flash drought during the first half of summer that reached its peak intensity by late summer, but then persisted for over a year in some locations following the end of the rapid intensification period. We do not propose that the entire event in such cases should be classified as a flash drought; rather, the term "flash drought" should be reserved for the time period during which the rapid intensification occurred. 
Because the proposed definition focuses on the intensification rate, it is necessary to use metrics depicting changes in some quantity over a period of time to identify a flash drought. It is also important to account for seasonal or regional climate characteristics that may make rapid decreases in soil moisture or some other quantity more or less likely to occur during certain times of the year. This could be accomplished in a variety of ways, such as simply requiring an index expressed as a percentile to decrease by a certain amount over a specified time period. An alternative approach is to use standardized change anomalies that depict how rapidly an index is changing with time relative to the local climatology for that time of the year. The severity of the flash drought could then be determined based on the magnitude of the change anomalies each week or over an extended period of time, similar to the approach used in the RCI. Regardless, a key requirement for identifying a flash drought is to choose a drought index that can respond quickly to rapidly changing conditions. For agricultural and ecological flash droughts, this typically means choosing drought indices computed over short time periods (e.g., $<1$ month) that are sensitive to soil moisture, ET, evaporative demand, or vegetation health, and then assessing changes in those indices during the past few weeks (Otkin et al. 2013).

As a second requirement, we propose that the chosen index must actually fall into drought during the rapid intensification period in order for the event to be classified as a flash drought. To be consistent with existing drought definitions, this means that the index must fall below the 20th percentile for the event to be considered flash drought because that is when abnormally dry conditions begin to have a large impact on the environment (Svoboda et al. 2002). By design, this requirement will lead to the exclusion of short periods characterized by rapid deterioration that do not actually lead to drought. Also, by not imposing a starting threshold on the drought index, a flash drought can initially develop even when the index originally depicts near-normal conditions. For example, a region containing adequate soil moisture could experience flash drought if large precipitation deficits quickly develop or there is a prolonged period of excessive atmospheric demand that leads to a rapid transition to water-limited conditions.

Similar to other drought types, flash droughts are characterized by a range of intensities, with the magnitude of the flash drought and its impacts on both managed and natural ecosystems largely determined by how quickly drought conditions develop, the magnitude of the observed changes, and whether or not long-term drought develops after the period of rapid intensification ends. Therefore, to better capture the full range of flash drought intensities, we propose that a suite of different magnitude and temporal change thresholds rather than a single universal definition should be used to identify them and to characterize their overall severity. For example, with the USDM, a two-category increase in drought severity over a 6-week period could be used to classify a flash drought as having moderate intensity, whereas a larger four-category change over a similar time period would represent a more severe flash drought event. Another approach would be to define the flash drought intensity based on the magnitude of standardized change anomalies and their persistence over multiweek periods as is done when computing the RCI (Otkin et al. 2015a). Likewise, Ford and Labosier (2017) chose to define "flash droughts" to be situations when soil moisture percentiles for a given location dropped from above the 40th percentile to below the 20 th percentile over a 20 -day period. That methodology could be expanded to include additional percentile and temporal change thresholds to capture a broader range of flash drought events. In contrast,

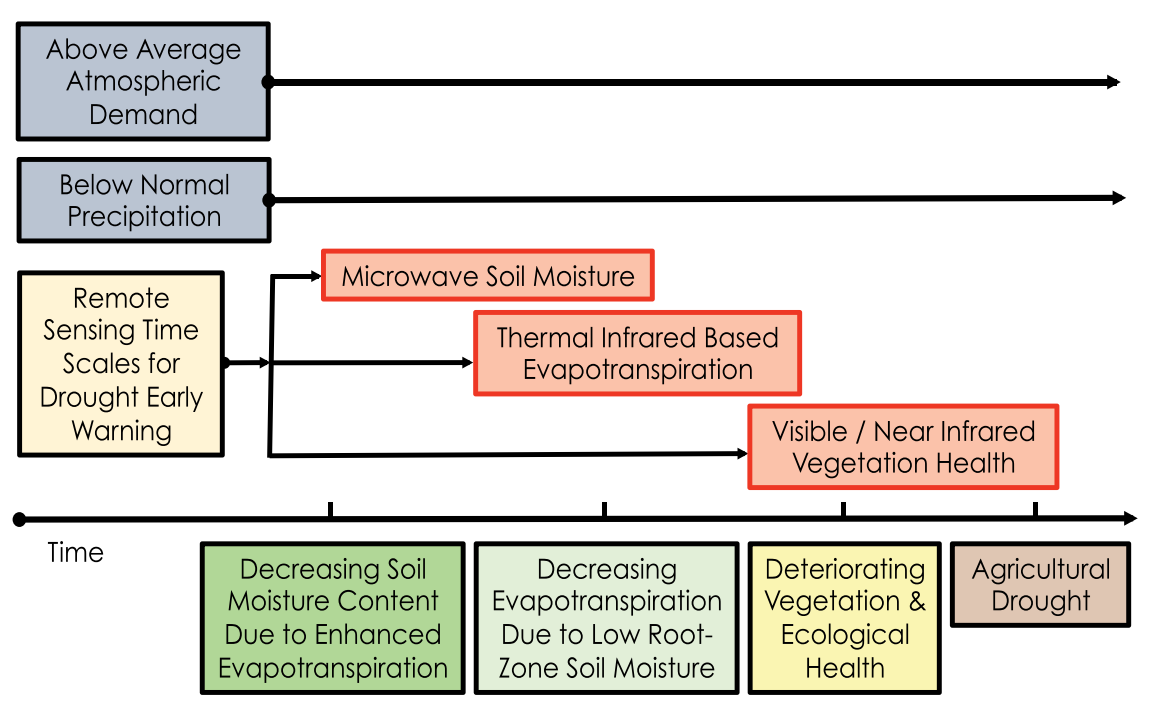

FIG. 2. Schematic overview showing the typical evolution of a flash drought event. The schematic is based on Fig. II.3 in Hobbins et al. (2017). 
Mo and Lettenmaier $(2015,2016)$ mandate that soil moisture must be below the 40th percentile during a single 5-day period for a flash drought to occur. Because their definition does not account for changes in soil moisture with time, nor is the threshold dry enough to actually be considered drought, we argue that their definition does not identify flash droughts and therefore its use should be discontinued.

\section{MONITORING THE EVOLUTION OF A} FLASH DROUGHT. Though the general characteristics of individual flash drought events, such as their intensification rate and severity, will vary from one event to another owing to differences in the antecedent conditions and the strength and persistence of the atmospheric anomalies driving their evolution, some guidelines regarding their evolution can still be constructed using results from prior studies. Figure 2 provides a schematic overview of a typical flash drought event. To effectively capture the onset and evolution of a flash drought, it is necessary to use a variety of drought monitoring tools depicting anomalies in soil moisture, ET, evaporative demand, and vegetation health. In general, flash drought onset is more likely to occur when the evaporative demand is much higher than normal for several weeks. New drought monitoring tools such as the evaporative demand drought index (EDDI; Hobbins et al. 2016; McEvoy et al. 2016) can be used to identify regions experiencing excessive atmospheric demand over different time scales and has been shown to provide early warning of flash drought development. A key requirement for a flash drought to develop, however, is that the enhanced atmospheric demand is not compensated for by increased precipitation. Thus, to properly account for deficits in the balance between supply and demand of surface moisture (e.g., precipitation minus PET), tools such as the standardized precipitation evapotranspiration index (Vicente-Serrano et al. 2010) that combine anomalies in precipitation and evaporative demand should be used because assessing each component separately may provide an incomplete indication of drought severity. Indeed, it is the juxtaposition of near- to below-normal precipitation and above-normal evaporative demand that leads to flash drought development.

During the onset phase of a flash drought, soil moisture deficits often develop in the topsoil layer first and then move deeper into the soil column; however, large deficits can also develop over a deeper layer if the vegetation has a deep root structure that can access subsoil moisture. Indeed, to cope with higher atmospheric demand, vegetation often accelerates flash drought development through a more rapid depletion of root-zone soil moisture due to enhanced ET. Satellite microwave sensors sensitive to soil moisture in the top $5 \mathrm{~cm}$ of the soil profile provide valuable information about drought onset, albeit with coarse horizontal resolution $(25-40 \mathrm{~km})$ and with limited direct information about root-zone moisture. Because of this, soil moisture monitoring networks and land surface models that provide soil moisture information over the entire root zone are critical for flash drought detection. Though ET may initially be enhanced owing to high evaporative demand, vegetation will begin to curtail its water usage as the soil moisture continues to decrease, thereby leading to water-limited conditions. Because ET anomalies may change sign from positive to negative during the onset of a flash drought, a clearer signal of the worsening conditions can be obtained using tools such as the ESI that depict anomalies in the potential ET fraction (ET/PET). Tools such as the ESI and EDDI are complementary to each other because drought signals often emerge earlier in EDDI, but at the expense of a high false-alarm rate because not all regions with unusually high evaporative demand will experience drought. The ESI can be used to better delineate which areas within a broad region of increased evaporative demand are actually experiencing moisture stress conditions. This is aided by the coupling between increased moisture stress and elevated land surface temperatures observed in the satellite thermal infrared imagery used to compute the ESI. As flash drought conditions continue to intensify, large soil moisture deficits develop over a deep layer of the soil column and often display a similar temporal evolution to the ESI given the tight coupling between soil moisture and ET.

As drought conditions become more severe, visible signs of moisture stress such as yellow or curled leaves become more apparent in the vegetation. These visible signs of deterioration tend to occur after the initial decreases in soil moisture and ET and are associated with decreases in leaf area index, gross primary productivity, and vegetation fraction. During severe drying, whereby the available water in the root zone is fully depleted, the vegetated canopy can experience temporary or permanent senescence, a dramatic reduction in $\mathrm{ET}$, and due to the loss of evaporative cooling via ET, localized thermal anomalies that further perpetuate drought conditions via elevated sensible heating. A representative example illustrating the rapid deterioration of vegetation health during a flash drought is shown in Fig. 3 using phenocam images from the Marena, Oklahoma, In Situ Sensor 
Marena, OK Phenocam - 01 July 2012

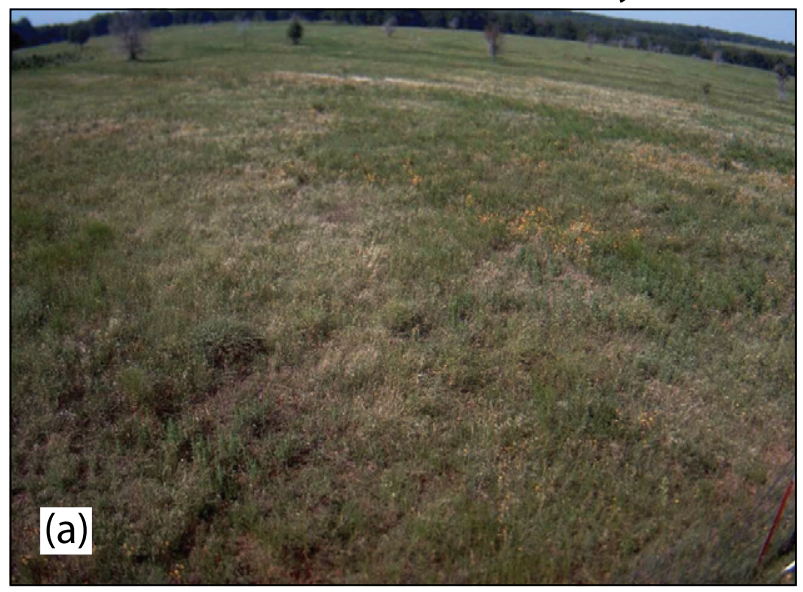

Marena, OK Phenocam - 01 July 2014

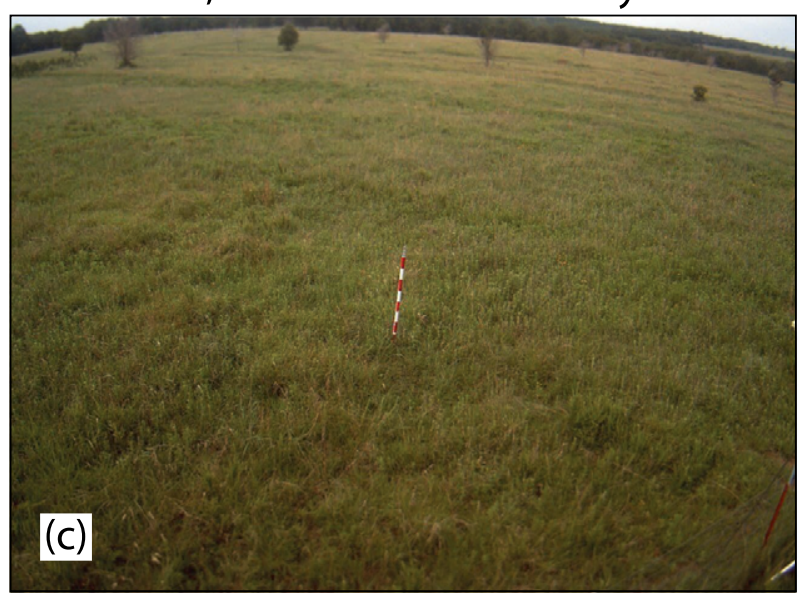

Marena, OK Phenocam - 11 August 2012

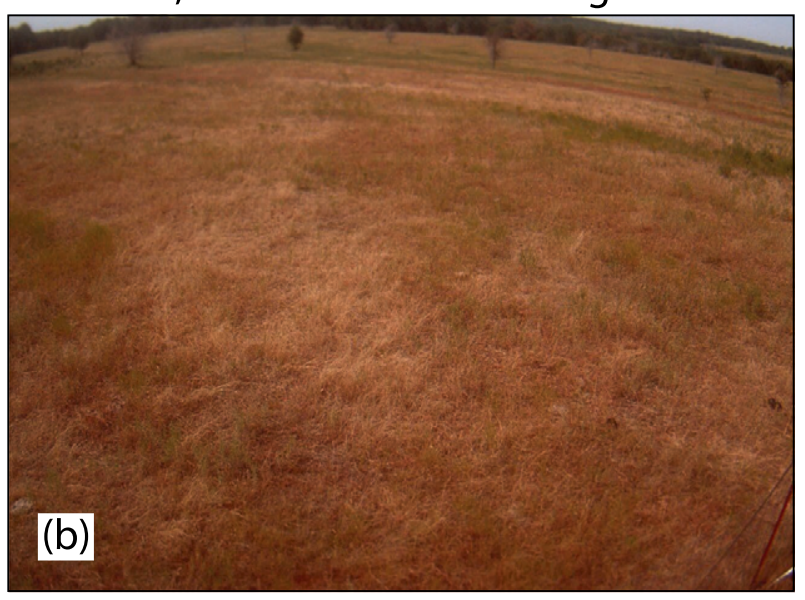

Marena, OK Phenocam - 11 August 2014

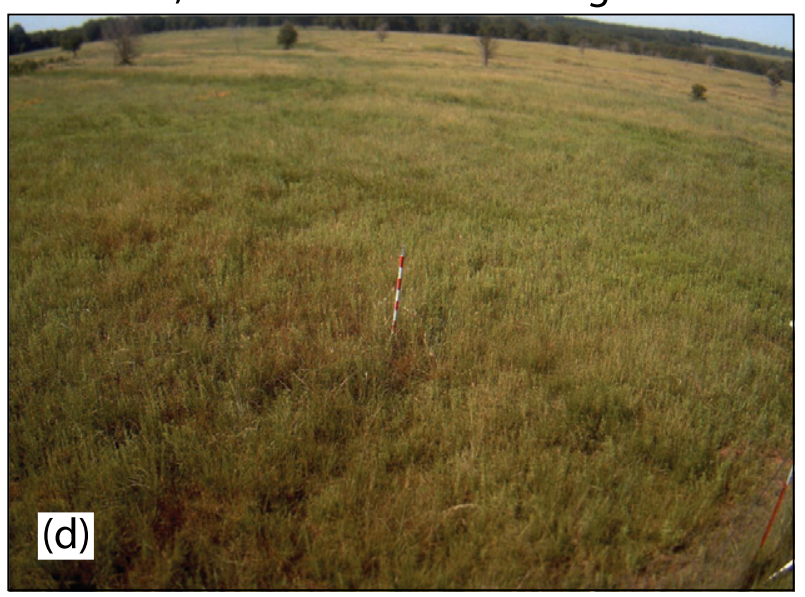

FIG. 3. Phenocam images taken at MOISST, which is adjacent to the Marena mesonet station, on (a) I Jul 20I2, (b) II Aug 2012, (c) I Jul 2014, and (d) II Aug 2014. All images were taken at 1030 local time.

Testbed (MOISST; Cosh et al. 2016). In this example, the 2012 flash drought caused the grasses to rapidly brown and go dormant over a 6-week period, which stands in sharp contrast to the continued greenness over the same time period in 2014. A wide assortment of satellite-derived tools, such as the normalized difference vegetation index (Tucker 1979), enhanced vegetation index (Huete et al. 2002), and land surface water index (Xiao et al. 2002), computed using visible and near-infrared satellite imagery, can be used to provide high-resolution estimates of vegetation health during flash drought events.

To summarize, a typical progression during either an agricultural or an ecological flash drought given adequate-to-surplus soil moisture (i.e., energylimited regime) is for an extended period of enhanced evaporative demand to initially cause an increase in ET as vegetation responds to the anomalous weather conditions, subsequently followed by a period of rapidly decreasing soil moisture content, a transition to water-limited conditions, reduced ET, and the subsequent emergence of visible signs of vegetation moisture stress. The intensification rate and final severity of a flash drought will be strongly influenced by the strength and persistence of the atmospheric anomalies forcing its evolution, the magnitude of the precipitation deficits, and the vulnerability of the crops or rangelands to drought. After the period of rapid intensification ends, a flash drought could potentially develop into hydrological drought or simply be terminated by a heavy precipitation event.

CONCLUDING REMARKS. Though the term "flash drought" first entered the scientific lexicon in the early 2000s to describe droughts that intensify more rapidly than conventional droughts, it did not become popularized until 2011 and 2012, when the media and scientific community began to extensively use the term when referring to the devastating droughts that affected parts of the central 
United States each of those years. Given its continued widespread use in the media to describe more recent droughts and its increasing use in journal articles, it is prudent to develop clear and consistent terminology that allows us to more effectively convey the characteristics of these events and the risks they may pose to vulnerable stakeholders. In recent years, however, two separate approaches have been used to identify flash droughts: one that focuses on the rate of intensification and another that focuses on duration. These conflicting notions for what constitutes a flash drought—rapid development versus short durationintroduce ambiguity that affects our ability to detect their onset, monitor their development, and forecast their evolution and demise.

Here, we have proposed that the definition for "flash drought" should inherently focus on its rate of intensification rather than its duration, with droughts that develop much more rapidly than normal being identified as flash droughts. By focusing on their unusually rapid rate of intensification, the definition clearly highlights their most salient characteristic. Given the spate of rapid-onset flash droughts in recent years and their large impact on farming and ranching, there is also an urgent need to enhance our ability to forecast these events. To capture their rapid onset, it is necessary to generate drought intensification forecasts at weekly intervals that depict changes in drought conditions over subseasonal time scales. In addition to improvements to climate models, new empirical forecasting methods such as those presented by Lorenz et al. $(2017 \mathrm{a}, \mathrm{b})$ that leverage the long-term memory of soil moisture and vegetation should be explored. Studies that increase our understanding of the role that atmosphere-land surface interactions play during flash drought development and the ability of land surface and climate models to depict their onset and evolution are also necessary. Finally, as discussed in Otkin et al. (2015b), stakeholder groups vulnerable to flash droughts desire monitoring and forecasting tools that are easy to use and deliver timely information. Having a consistent definition for what constitutes a flash drought enhances our ability to provide stakeholders useful information and promotes a more thorough understanding of these important features of the climate system.

ACKNOWLEDGMENTS. The authors would like to acknowledge support provided by the NOAA Climate Program Office (CPO) Modeling, Analysis, Predictions, and Projections program under Grant NA14OAR4310226, the NOAA CPO Sectoral Applications Research Program under Grants NA16OAR4310130 and NA13OAR4310122, and the USDA National Institute of Food and Agriculture under
Grant 2013-69002-23146. The authors also want to thank two anonymous reviewers and the editor for their thorough reviews that helped improve the clarity of the manuscript.

\section{REFERENCES}

Anderson, M. C., J. M. Norman, J. R. Mecikalski, J. A. Otkin, and W. P. Kustas, 2007: A climatological study of evapotranspiration and moisture stress across the continental U.S. based on thermal remote sensing: 1. Model formulation. J. Geophys. Res., 112, D10117, https://doi.org/10.1029/2006JD007506.

-, C. Hain, J. A. Otkin, X. Zhan, K. Mo, M. Svoboda, B. Wardlow, and A. Pimstein, 2013: An intercomparison of drought indicators based on thermal remote sensing and NLDAS simulations. J. Hydrometeor., 14, 1035-1056, https://doi.org/10.1175 /JHM-D-12-0140.1.

— - and Coauthors, 2016: Assessing correlations of satellite-derived evapotranspiration, precipitation, and leaf area index anomalies with yields of major Brazilian crops. Remote Sens. Environ., 174, 82-99, https://doi.org/10.1016/j.rse.2015.11.034.

Cosh, M. H., and Coauthors, 2016: The Soil Moisture Active Passive Marena, Oklahoma, In Situ Sensor Testbed (SMAP-MOISST): Testbed design and evaluation of in situ sensors. Vadose Zone J., 15, https:// doi.org/10.2136/vzj2015.09.0122.

Crausbay, S. D., and Coauthors, 2017: Defining ecological drought for the twenty-first century. Bull. Amer. Meteor. Soc., 98, 2543-2550, https://doi.org/10.1175 /BAMS-D-16-0292.1.

Ford, T. W., and C. F. Labosier, 2017: Meteorological conditions associated with the onset of flash drought in the eastern United States. Agric. For. Meteor., 247, 414423, https://doi.org/10.1016/j.agrformet.2017.08.031.

- , D. B. McRoberts, S. M. Quiring, and R. E. Hall, 2015: On the utility of in situ soil moisture observations for flash drought early warning in Oklahoma, USA. Geophys. Res. Lett., 42, 9790-9798, https://doi .org/10.1002/2015GL066600.

Hobbins, M. T., A. Wood, D. McEvoy, J. Huntington, C. Morton, M. C. Anderson, and C. Hain, 2016: The Evaporative Demand Drought Index: Part I: Linking drought evolution to variations in evaporative demand. J. Hydrometeor., 17, 1745-1761, https://doi .org/10.1175/JHM-D-15-0121.1.

—-, D. McEvoy, and C. Hain, 2017: Evapotranspiration, evaporative demand, and drought. Drought and Water Crises: Science, Technology, and Management Issues, D. Wilhite and R. Pulwarty, Eds., CRC Press, 259-288.

Huete, A., K. Didan, T. Miura, E. P. Rodriguez, X. Gao, and L. G. Ferreira, 2002: Overview of the radiometric 
and biophysical performance of the MODIS vegetation indices. Remote Sens. Environ., 83, 195-213, https://doi.org/10.1016/S0034-4257(02)00096-2.

Hunt, E., K. G. Hubbard, D. A. Wilhite, T. J. Arkebauer, and A. L. Dutcher, 2009: The development and evaluation of a soil moisture index. Int. J. Climatol., 29, 747-759, https://doi.org/10.1002/joc.1749.

—, M. Svoboda, B. Wardlow, K. Hubbard, M. J. Hayes, and T. Arkebauer, 2014: Monitoring the effects of rapid onset of drought on non-irrigated maize with agronomic data and climate-based drought indices. Agric. For. Meteor., 191, 1-11, https://doi .org/10.1016/j.agrformet.2014.02.001.

Lorenz, D. J., J. A. Otkin, M. Svoboda, C. Hain, M. C. Anderson, and Y. Zhong, 2017a: Predicting U.S. Drought Monitor (USDM) states using precipitation, soil moisture, and evapotranspiration anomalies. Part I: Development of a nondiscrete USDM index. J. Hydrometeor., 18, 1943-1962, https://doi.org/10.1175/JHM-D-16-0066.1.

,,,,----- , and,$- 2017 \mathrm{~b}$ : Predicting U.S. Drought Monitor (USDM) states using precipitation, soil moisture, and evapotranspiration anomalies. Part II: Intraseasonal drought intensification forecasts. J. Hydrometeor., 18, 1963-1982, https:// doi.org/10.1175/JHM-D-16-0067.1.

Lydolph, P. E., 1964: The Russian Sukhovey. Ann. Assoc. Amer. Geogr., 54, 291-309, https://doi.org/10.1111 /j.1467-8306.1964.tb00490.x.

McEvoy, D. J., J. L. Huntington, M. T. Hobbins, A. Wood, C. Morton, M. Anderson, and C. Hain, 2016: The Evaporative Demand Drought Index. Part II: CONUS-wide assessment against common drought indicators. J. Hydrometeor., 17, 1763-1779, https:// doi.org/10.1175/JHM-D-15-0122.1.

Mo, K. C., and D. P. Lettenmaier, 2015: Heat wave flash droughts in decline. Geophys. Res. Lett., 42, 2823-2829, https://doi.org/10.1002/2015GL064018.

$-, \ldots, 2016$ : Precipitation deficit flash droughts over the United States. J. Hydrometeor., 17, 1169-1184, https://doi.org/10.1175/JHM-D-15-0158.1.

Mozny, M., M. Trnka, Z. Zalud, P. Hlavinka, J. Nekovar, V. Potop, and M. Virag, 2012: Use of a soil moisture network for drought monitoring in the Czech Republic. Theor. Appl. Climatol., 107, 99-111, https:// doi.org/10.1007/s00704-011-0460-6.

National Centers for Environmental Information, 2017: Billion-dollar weather and climate disasters: Overview. NOAA NCEI, https://ncdc.noaa.gov/billions/.

Otkin, J. A., M. C. Anderson, C. Hain, I. Mladenova, J. Basara, and M. Svoboda, 2013: Examining flash drought development using the thermal infrared based evaporative stress index. J. Hydrometeor., 14, 1057-1074, https://doi.org/10.1175/JHM-D-12-0144.1.
,,--- , and M. Svoboda, 2014: Examining the relationship between drought development and rapid changes in the evaporative stress index. $J$. Hydrometeor., 15, 938-956, https://doi.org/10.1175/ JHM-D-13-0110.1.

,,$-- \ldots$, and,$- 2015 \mathrm{a}$ : Using temporal changes in drought indices to generate probabilistic drought intensification forecasts. J. Hydrometeor., 16, 88-105, https://doi.org/10.1175/JHM-D-14-0064.1.

—, M. Shafer, M. Svoboda, B. Wardlow, M. C. Anderson, C. Hain, and J. Basara, 2015b: Facilitating the use of drought early warning information through interactions with agricultural stakeholders. Bull. Amer. Meteor. Soc., 96, 1073-1078, https://doi.org/10.1175 /BAMS-D-14-00219.1.

— , and Coauthors, 2016: Assessing the evolution of soil moisture and vegetation conditions during the 2012 United States flash drought. Agric. For. Meteor., 218-219, 230-242, https://doi.org/10.1016/j .agrformet.2015.12.065.

Seneviratne, S. I., T. Corti, E. L. Davin, M. Hirschi, E. B. Jaeger, I. Lehner, B. Orlowsky, and A. J. Teuling, 2010: Investigating soil moisture-climate interactions in a changing climate: A review. Earth-Sci. Rev., 99, 125161, https://doi.org/10.1016/j.earscirev.2010.02.004.

Svoboda, M., and Coauthors, 2002: The Drought Monitor. Bull. Amer. Meteor. Soc., 83, 1181-1190, https:// doi.org/10.1175/1520-0477(2002)083<1181:TDM>2 .3.CO;2.

Tucker, C. J., 1979: Red and photographic infrared linear combinations for monitoring vegetation. Remote Sens. Environ., 8, 127-150, https://doi .org/10.1016/0034-4257(79)90013-0.

Vicente-Serrano, S. M., S. Begueria, and J. I. LopezMoreno, 2010: A multiscalar drought index sensitive to global warming: The standardized precipitation evapotranspiration index. J. Climate, 23, 1696-1718, https://doi.org/10.1175/2009JCLI2909.1.

Wang, L., X. Yuan, Z. Xie, P. Wu, and Y. Li, 2016: Increasing flash droughts over China during the recent global warming hiatus. Sci. Rep., 6, 30571, https://doi.org/10.1038/srep30571.

Wilhite, D. A., and M. H. Glantz, 1985: Understanding the drought phenomenon: The role of definitions. Water Int., 10, 111-120, https://doi .org/10.1080/02508068508686328.

Xiao, X., S. Boles, J. Liu, D. Zhuang, and M. Liu, 2002: Characterization of forest types in northeastern China, using multi-temporal SPOT-4 VEGETATION sensor data. Remote Sens. Environ., 82, 335-348, https://doi.org/10.1016/S0034 -4257(02)00051-2. 


\section{AMS Members}

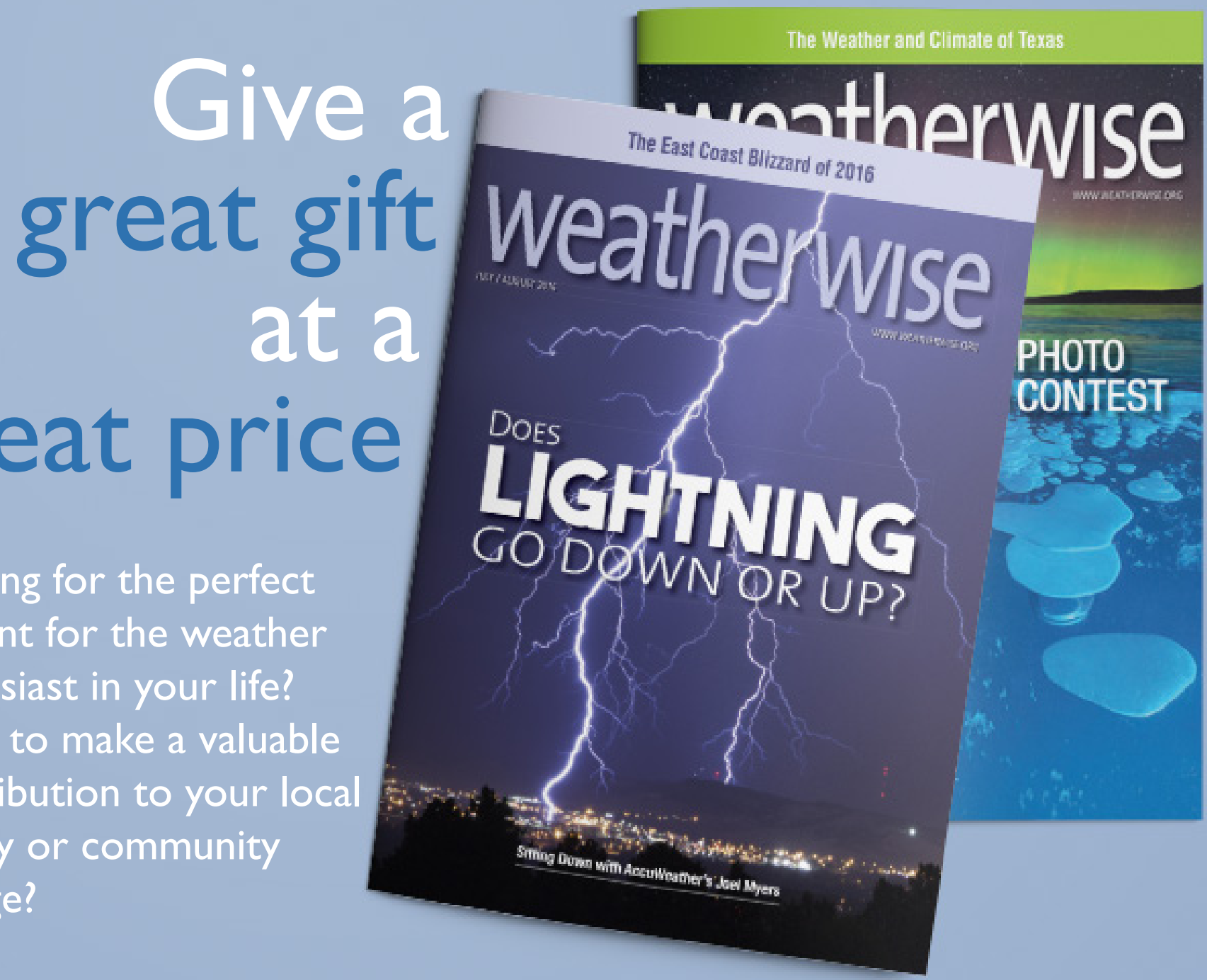

Send a subscription to Weatherwise magazine for just $\$ 24.95 *$-That's nearly

$50 \%$ off the list price!

Contact Member Services by e-mail at amsmem@ametsoc.org or by phone at 617-227-2425 to place all of your Weatherwise orders today!
Written for a general audience, Weatherwise offers a colorful and nontechnical look at recent discoveries in meteorology and climatology.

Check out the latest table of contents at www.weatherwise.org.

\section{Want your own?}

Then order a personal subscription at the same great price. 